\title{
First case of imported chikungunya infection in Croatia, 2016
}

\author{
Boris Luksic, ,,2 Nenad \\ Pandak, 2,3 Edita Drazic- \\ Maras,' Svjetlana Karabuva,' \\ Mislav Radic, ${ }^{2,4}$ Andrea \\ Babic-Erceg, ${ }^{5}$ Ljubo Barbic, ${ }^{6}$ \\ Vladimir Stevanovic, ${ }^{6}$ \\ Tatjana Vilibic-Cavlek ${ }^{5,7,8}$ \\ 'Clinical Department of Infectious \\ Diseases, University Hospital Centre \\ Split, Split, Croatia; ${ }^{2}$ School of \\ Medicine, University of Split, Split, \\ Croatia; ${ }^{3}$ Department of Infectious \\ Diseases, General Hospital "Dr Josip \\ Bencevic", Slavonski Brod, Croatia; \\ ${ }^{4}$ Department of Rheumatology and \\ Clinical Immunology, University \\ Hospital Centre Split, Split, Croatia ; \\ ${ }^{5}$ Croatian National Institute of Public \\ Health, Zagreb, Croatia; ${ }^{6}$ Department \\ of Microbiology and Infectious \\ Diseases with Clinic, Faculty of \\ Veterinary Medicine, University of \\ Zagreb, Zagreb, Croatia; ${ }^{7}$ Reference \\ Centre for Diagnosis and Surveillance \\ of Viral Zoonoses of the Ministry of \\ Health of the Republic of Croatia, \\ Zagreb, Croatia; ${ }^{8}$ School of Medicine, \\ University of Zagreb, Zagreb, Croatia
}

Correspondence: Nenad Pandak Department of Infectious Diseases, General Hospital "Dr Josip Bencevic", Andrije Stampara 42, 35000 Slavonski Brod, Croatia

Email npandak@gmail.com
This article was published in the following Dove Press journal:

International Medical Case Reports Journal

3 April 2017

Number of times this article has been viewed

\begin{abstract}
In recent years, several European countries reported cases of imported chikungunya infection. We present the first imported clinically manifested chikungunya fever in Croatia. A 27-year-old woman returned to Croatia on 21 March 2016, after she stayed in Costa Rica for two months where she had noticed a mosquito bite on her left forearm. Five days after the mosquito bite she developed severe arthralgias, fever and erythematous papular rash. In next few days symptoms gradually subsided. After ten days she felt better, but arthralgias re-appeared accompanied with morning stiffness. Two weeks after the onset of the disease she visited the infectious diseases outpatient department. The physical examination revealed rash on the trunk, extremities, palms and soles. Laboratory findings showed slightly elevated liver transaminases. Serological tests performed on day 20 after disease onset showed a high titer of chikungunya virus (CHIKV) IgM and IgG antibodies which indicated CHIKV infection. CHIKV-RNA was not detected. Serology to dengue and Zika virus was negative. The patient was treated with nonsteroid anti-inflammatory drugs and paracetamol. Her symptoms ameliorated, however, three months later she still complaint of arthralgias. The presented case highlights the need for inclusion of CHIKV in the differential diagnosis of arthralgia in all travelers returning from countries with documented CHIKV transmission.
\end{abstract}

Keywords: chikungunya, imported, Croatia

\section{Introduction}

Chikungunya fever is a mosquito-borne emerging viral disease caused by chikungunya virus (CHIKV), which belongs to the genus Alphavirus of the family Togaviridae. It is endemic in many parts of Africa and Asia where seroprevalence rates reach $75 \%{ }^{1}$ In Africa, the virus maintains a sylvatic cycle between nonhuman primates and forestdwelling mosquitoes, while in Asia transmission of CHIKV occurs in an urban cycle involving humans and Aedes spp. mosquitoes (Ae. aegypti, Ae. albopictus). ${ }^{2}$ Typical clinical symptoms of chikungunya include fever, headache, myalgia, rash, and arthralgia. The symptoms, particularly joint pain, can be severe and long lasting in many patients. ${ }^{3}$

In many European countries, imported cases of chikungunya were repeatedly reported. ${ }^{4-7}$ First, autochthonous CHIKV cases were reported during the 2007 outbreak and involved more than 200 cases in the Ravenna Province, Italy. ${ }^{8,9}$ In 2014, an outbreak including $12 \mathrm{CHIKV}$ cases occurred in Montpelier, France. ${ }^{10}$ In Croatia, CHIKV antibodies were sporadically detected in travelers from endemic areas. A seroepidemiological study conducted during 2011-2012 showed that $0.9 \%$ inhabitants of the Croatian littoral are seropositive to CHIKV. ${ }^{11}$ We report the first detection of an imported, clinically manifested case of chikungunya fever in Croatia. 


\section{Case report}

\section{Clinical presentation and laboratory findings}

On March 26, 2016, a 27-year-old woman visited the infectious diseases outpatient department because of persistent arthralgias and rash. She works as a stewardess on a cruise ship and she stayed in Costa Rica for 2 months where she developed symptoms; then she returned to Croatia on March 21. Six months before this illness, she was vaccinated against yellow fever. She remembered a mosquito bite on her left forearm because she noticed a little hematoma around the indurated papule which she had not experienced after earlier mosquito bites. Five days after the mosquito bite, on the first day of her disease, she felt symmetrical arthralgias in her ankles, knees, wrists, and elbows but also in small joints of her hands and feet. The third day, she developed high fever up to $38.5^{\circ} \mathrm{C}$ with chills. Her arthralgias deteriorated, so she could hardly walk. On the fifth day of her illness, an itchy rash appeared on her trunk, and the next day it extended to her face, extremities, as well as palms and soles. The erythematous papular rash subsided in the next 2 days. At the same time, she became afebrile, while arthralgias remained up to the tenth day of her illness after which she was feeling well, but exhausted. During the acute phase of her illness, she had nausea and she had a few loose stools too. Ten days after she had recovered, severe arthralgias in her ankles, elbows, right shoulder, and in the small joints of hands and feet reappeared. She also complained about morning stiffness lasting for 10-30 min.

On the initial visit (day 15 after the disease onset), the physical examination was normal except for rash on the trunk, extremities, palms, and soles (Figure 1). Routine laboratory tests were normal, except for slightly elevated liver transaminases, erythrocytes $4.35 \times 10^{12} / \mathrm{L}$ (reference range [RR]: 3.86-5.08), leukocytes $8.4 \times 10^{9} / \mathrm{L}$ (RR: 83.4-9.7), lymphocytes $21.5 \%$ (RR: $20-46$ ), C-reactive protein $1.3 \mathrm{mg} / \mathrm{L}(<5)$, platelets $219 \times 10^{9} / \mathrm{L}$ (RR: 158-424), BUN $5.4 \mathrm{mmol} / \mathrm{L}$ (RR: 2.8-8.3), creatinine $70 \mu \mathrm{mol} / \mathrm{L}$ (RR: 63-107), aspartate aminotransferase $32 \mathrm{U} / \mathrm{L}$ (RR: 8-30), alanine aminotransferase $51 \mathrm{U} / \mathrm{L}$ (RR: $10-36$ ), $\gamma$-glutamyl transferase $21 \mathrm{U} / \mathrm{L}$ (RR: 9-35), and lactate dehydrogenase 196 U/L (RR: 25-241).

According to the case definition proposed by the international chikungunya expert group (2015), which distinguishes 4 chikungunya case categories; acute clinical case, atypical case, severe acute case, and suspected and/or confirmed chronic case; ${ }^{12}$ our patient was classified as a confirmed chronic chikungunya case. The patient was treated with nonsteroidal anti-inflammatory drugs and paracetamol. She was regularly followed up during the next few months in order to treat her arthralgias and also to observe the progress of her illness. Her symptoms ameliorated, but 3 months later she still reports arthralgias.

\section{Virological results}

Due to similar geographical distribution and clinical symptoms, the serum sample (taken on day 20) was initially tested for CHIKV IgM/IgG antibodies, using indirect immunofluorescent assay (IFA; Euroimmun, Lübeck, Germany) as well as Zika virus (ZIKV) IgM/IgG and dengue virus (DENV) IgM/ IgG antibodies using enzyme-linked immunosorbent assay (ELISA; Euroimmun). To exclude potential cross reactivity with other arboviruses, the sample was additionally tested for West Nile virus (WNV) and Usutu virus (USUV) antibodies using ELISA (Euroimmun), as well as yellow fever virus (YFV), Japanese encephalitis virus (JEV), and tickborne encephalitis virus (TBEV) using IFA (Euroimmun). Serology results are presented in Table 1. CHIKV IgM and IgG antibodies were detected with titre 1:100 and 1:10,000, respectively (Figure 2). In addition, postvaccinal YFV IgG antibodies were found (titer 100). There was no cross reactivity with other tested arboviruses.
A

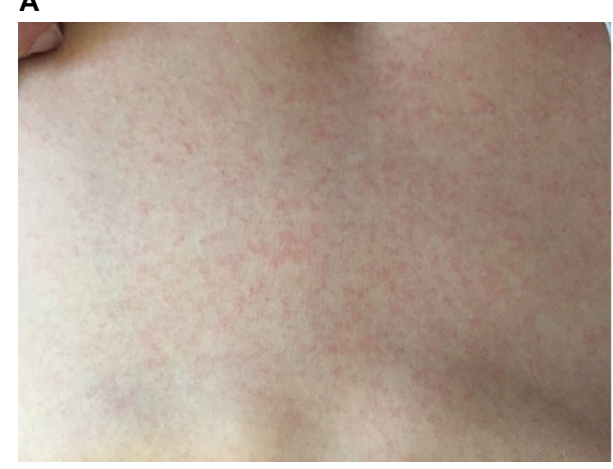

B

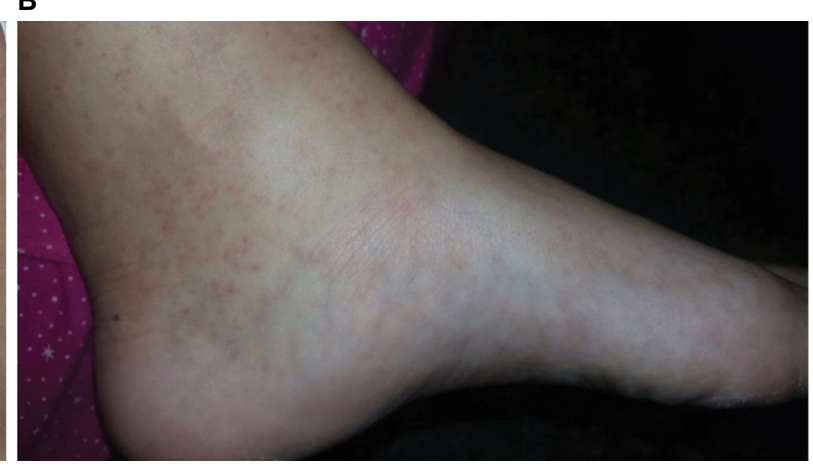

C

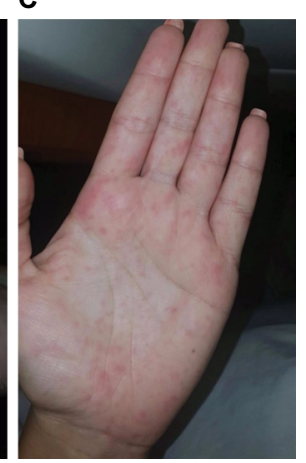

Figure I Rash on patient with chikungunya infection.

Notes: (A) Trunk, (B) foot, and (C) palm. 
Table I Serology results of patient with chikungunya infection

\begin{tabular}{lllll}
\hline Virus & $\begin{array}{l}\text { ELISA IgM } \\
\text { (ratio) }^{\mathbf{a}}\end{array}$ & $\begin{array}{l}\text { ELISA IgG } \\
\mathbf{( R U / m L )}^{\mathbf{b}}\end{array}$ & $\begin{array}{l}\text { IFA IgM } \\
\text { (titer) }\end{array}$ & $\begin{array}{l}\text { IFA IgG } \\
\text { (titer) }\end{array}$ \\
\hline $\begin{array}{l}\text { Chikungunya } \\
\text { Dengue }\end{array}$ & ND & ND & I00 & I0,000 \\
Zika & Negative (0.69) & Negative (3) & ND & ND \\
West Nile & Negative (0.57) & Negative (5) & Negative & Negative \\
Usutu & ND & Negative (<2) & ND & ND \\
$\begin{array}{l}\text { Japanese } \\
\text { encephalitis }\end{array}$ & ND & ND & Negative & Negative \\
Yellow fever & ND & ND & Negative & I00 \\
$\begin{array}{l}\text { Tick-borne } \\
\text { encephalitis }\end{array}$ & ND & ND & Negative & Negative \\
\hline
\end{tabular}

Notes: agM ratio $<0.8$ negative, $0.8-1$.I borderline, $>$ I.I positive; 'اgG $R U<16$ negative, 16-22 borderline, $>22$ positive.

Abbreviation: ELISA, enzyme-linked immunosorbent assay; IFA, indirect immunofluorescence assay; ND, not determined; RU, relative unit.

In addition, the sample was tested for the presence of CHIKV RNA using a qualitative real-time reverse transcriptase-polymerase chain reaction (RT-PCR) according to the protocol described by Smith et al. ${ }^{13}$ For nucleic acid isolation, an automated system QIAxtractor (QIAGEN, Hilden, Germany) was used. Real-time RT-PCR was performed using a single-tube RT-PCR test kit (Invitrogen SuperScript ${ }^{\mathrm{TM}} \mathrm{III}$ Platinum ${ }^{\circledR}$ One-Step Qualitative Kit; Carlsbad, CA, USA). The amplification and detection were performed with 7500 Real Time PCR System (Applied Biosystems, Foster City, $\mathrm{CA}, \mathrm{USA}$ ). The test tube contained a $25-\mu \mathrm{L}$ reaction mixture which included $5 \mu \mathrm{L}$ of isolated RNA, $0.2 \mu \mathrm{M}$ forward primer (CCGAAAGGAAACTTCAAAGCAACT), $0.2 \mu \mathrm{M}$ reverse primer (CAGATGCCCGCCATTATTGAT), and $0.1 \mu \mathrm{M}$ probe (FAM-GGGAGGTGGAGCATG-MGB). The reaction mixture was exposed to a $30 \mathrm{~min} 50^{\circ} \mathrm{C}$ reverse transcription step, $2 \mathrm{~min}$ of Taq activation at $95^{\circ} \mathrm{C}$, and 50 cycles consisting of $95^{\circ} \mathrm{C}$ for $15 \mathrm{sec}$ and $55^{\circ} \mathrm{C}$ for $32 \mathrm{sec}$. No CHIKV RNA was found in the tested sample. Sensitivity of the RT-PCR is reported to be high (0.3 plaque-forming units; $\mathrm{PFU} / \mathrm{mL}$ ), as is specificity (no cross reactivity with the most common alphaviruses that contained a minimum of $3 \log _{10}$ PFU of heterologous viral RNA). ${ }^{13}$

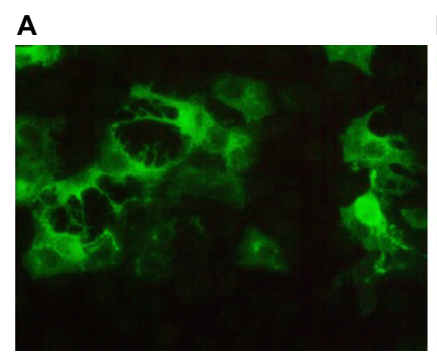

$1: 100$

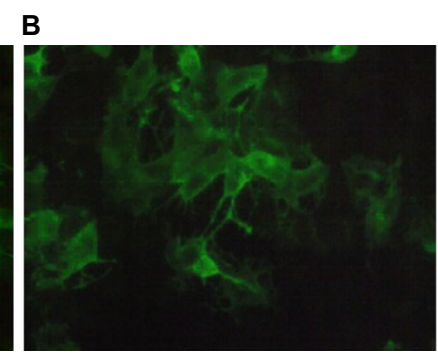

$1: 1,000$

\section{Discussion}

After a bite from an infected mosquito, CHIKV rapidly spreads in the body eventually causing acute illness. It is known that up to $18 \%$ of infected patients, usually those younger than 25 years, are asymptomatic. ${ }^{14}$ After the resolution of the acute illness symptoms, myalgias and arthralgias may persist for weeks, months, and even years. The proportion of patients suffering from the chronic form of disease that can be attributed to CHIKV infection varies between studies. In Singapore, $13 \%$ of patients had arthralgias 3 months after the acute phase, while $49 \%$ of patients from India had arthralgia 10 months after disease onset. After the outbreak of chikungunya in Italy, $70 \%$ of patients reported persistent arthralgias after six months and after 12 months, and chronic symptoms were present in $32 \%$ of patients. ${ }^{15}$ Severe arthralgia with morning stiffness was the most prominent symptom in our patient, too. Three months after disease onset, she still reported arthralgia.

Lymphopenia and thrombocytopenia are the most commonly detected pathologic laboratory findings associated with CHIKV infection. In the Reunion Island outbreak, lymphopenia was observed in $79 \%$ and moderate thrombocytopenia in $40 \%-50 \%$ of chikungunya patients. ${ }^{16}$ In our case, the only abnormal laboratory findings were slightly elevated liver enzymes, a finding that has been less commonly reported during chikungunya fever. Lymphocyte count was normal, but at the lower limit of the normal range. Similarly, leukopenia and thrombocytopenia were uncommon in imported CHIKV cases in Italy during 2006. ${ }^{17}$

Knowledge about the time period between the infection and the onset of symptoms is crucial as it can improve measures to prevent spreading of vector-borne infections. The incubation period in our patient was exactly 5 days, as she recalls the day when she had the mosquito bite. CHIKV viremia is usually short-lived (5 to 6 days), and so RT-PCR is most sensitive when performed within a week after disease onset. However, a study from Indonesia showed that duration
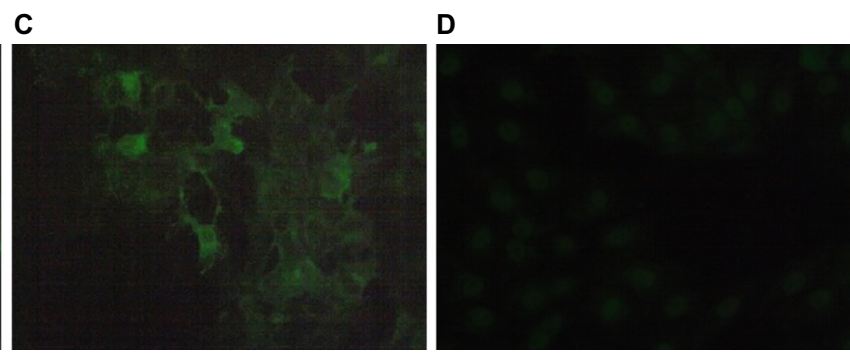

$1: 10,000$

Negative

CHIKV IgG

Figure 2 Indirect immunofluorescence assay of blood sample from a patient with chikungunya infection. (A) Dilution I:100; (B) dilution I:I,000; (C) dilution I:I0,000; and (D) negative control. 
of viremia during chikungunya was extended as early as 6 days prior until 13 days post-onset of fever. ${ }^{18}$ This observation suggests the possibility that our patient was viremic when she returned to Croatia and that she could have been a CHIKV reservoir, representing the possible threat for transmission and spreading of CHIKV, since one of the main vector, Ae. albopictus, is established in this area. ${ }^{11}$ RT-PCR was performed to confirm the presence of viremia; however, CHIKV RNA was not detected. Since the sample was collected in the post-acute phase and both CHIKV IgM and IgG antibodies were documented, the probability to detect viral RNA was low.

Serology is the most commonly used method for diagnosis of arboviral infections. Due to similar clinical symptoms and possible coinfections, ${ }^{19} \mathrm{CHIKV}$, DENV, and ZIKV were included in differential diagnosis in our patient. High titer of CHIKV IgM and IgG antibodies as well as negative DENV and ZIKV serology indicated CHIKV infection.

In recent years, the risk of CHIKV emergence in Europe is increasing, as imported cases of chikungunya are continuously reported. Any country where Aedes mosquito is present represents a potential area for future chikungunya outbreaks. Climate changes modeling and Ae. albopictus distribution maps showed that hot spots for establishment of this mosquito species in Europe are southern France, the northern and northeastern coasts of Spain, Portugal, Italy, the eastern coasts of the Adriatic, and western Turkey. During the last 2 decades, mosquito climate suitability has significantly increased over the southern UK, northern France, the Benelux, parts of Germany, Italy, Sicily, Slovenia, Croatia, and Bosnia and Herzegovina. ${ }^{20}$ It has been observed that the elimination of invasive mosquito species such as Ae. albopictus is extremely difficult, if possible at all. Considering the intensive airline travel between Europe and other parts of the world, it is almost just a question of when chikungunya will emerge as an autochthonous disease in Europe. In Croatia, this situation already happened with dengue in $2010 ;{ }^{21}$ therefore, there is a great possibility that the same scenario will happen with $\mathrm{CHIKV}$, since a competent vector Ae. albopictus is present in Croatia. Control measures should be regularly performed, particularly in areas with established Ae. albopictus population.

\section{Conclusion}

Detection of imported chikungunya fever in Croatia highlights the need for clinicians to consider chikungunya in the differential diagnosis of arthralgia in all persons returning from areas where CHIKV transmission is documented.

\section{Acknowledgment}

Written and signed informed consent for publication of this case report as well as the accompanying images was obtained from the patient.

\section{Disclosure}

The authors report no conflicts of interest in this work.

\section{References}

1. Sergon K, Njuguna C, Kalani R, et al. Seroprevalence of Chikungunya virus (CHIKV) infection on Lamu Island, Kenya, October 2004. Am J Trop Med Hyg. 2008;78(2):333-337.

2. Thiboutot MM, Kannan S, Kawalekar OU, et al. Chikungunya: a potentially emerging epidemic? PLoS Negl Trop Dis. 2010;4(4):e623.

3. Pfeffer M, Zöller G, Essbauer S, et al. Clinical and virological characterization of imported cases of Chikungunya fever. Wien Klin Wochenschr. 2008;120(19-20):95-100.

4. Bottieau E, Van Esbroeck M, Cnops L, Clerinx J, Van Gompel A. Chikungunya infection confirmed in a Belgian traveller returning from Phuket (Thailand). Euro Surveill. 2009;14(25).pii:19248.

5. Receveur M, Ezzedine K, Pistone T, Malvy D. Chikungunya infection in a French traveller returning from the Maldives, October, 2009. Euro Surveill. 2010;15(8):19494.

6. Tsiodras S, Pervanidou D, Papadopoulou E, et al. Imported Chikungunya fever case in Greece in June 2014 and public health response. Pathog Glob Health. 2016;110(2):68-73.

7. Rossini G, Gaibani P, Vocale C, Finarelli AC, Landini MP. Increased number of cases of Chikungunya virus (CHIKV) infection imported from the Caribbean and Central America to northern Italy, 2014. Epidemiol Infect. 2016;144(9):1912-1916.

8. Rezza G, Nicoletti L, Angelini R, et al; CHIKV study group. Infection with chikungunya virus in Italy: an outbreak in a temperate region. Lancet. 2007; 370(9602):1840-1846.

9. Angelini R, Finarelli AC, Angelini P, et al. An outbreak of chikungunya fever in the province of Ravenna, Italy. Euro Surveill. 2007; 12(9):E070906.1.

10. Delisle E, Rousseau C, Broche B, et al. Chikungunya outbreak in Montpellier, France, September to October 2014. Euro Surveill. 2015;20(17). pii:21108.

11. Vilibic-Cavlek T, Pem-Novosel I, Kaic B, et al. Seroprevalence and entomological study on chikungunya virus at the Croatian littoral. Acta Microbiol Immunol Hung. 2015;62(2):199-206.

12. WHO. Chikungunya: case definitions for acute, atypical and chronic cases. Conclusions of an expert consultation, Managua, Nicaragua, 20-21 May 2015. Wkly Epidemiol Rec. 2015;90:410-414.

13. Smith DR, Lee JS, Jahrling J, et al. Development of field-based real-time reverse transcription-polymerase chain reaction assays for detection of Chikungunya and O'nyong-nyong viruses in mosquitoes. Am J Trop Med Hyg. 2009;81(4):679-684.

14. Sissoko D, Moendandze A, Malvy D, et al. Seroprevalence and risk factors of chikungunya virus infection in Mayotte, Indian Ocean, 20052006: a population-based survey. PLoS One. 2008;3:e3066.

15. Dupuis-Maguiraga L, Noret M, Brun S, Le Grand R, Gras G, Roques P. Chikungunya disease: infection-associated markers from the acute to the chronic phase of arbovirus-induced arthralgia. PLoS Negl Trop Dis. 2012;6:e1446.

16. Thiberville SD, Boisson V, Gaudart J, Simon F, Flahault A, de Lamballerie X. Chikungunya fever: a clinical and virological investigation of outpatients on Reunion Island, South-West Indian Ocean. PLoS Negl Trop Dis. 2013;7(1):e2004.

17. Beltrame A, Angheben A, Bisoffi Z, et al. Imported chikungunya infection, Italy. Emerg Infect Dis. 2007;13(8):1264-1266. 
18. Riswari SF, Ma'roef CN, Djauhari H, et al. Study of viremic profile in febrile specimens of chikungunya in Bandung, Indonesia. J Clin Virol. 2016;74:61-65.

19. Villamil-Gómez WE, González-Camargo O, Rodriguez-Ayubi J, ZapataSerpa D, Rodriguez-Morales AJ. Dengue, chikungunya and Zika co-infection in a patient from Colombia. J Infect Public Health. 2016;9(5):684-686.
20. Caminade C, Medlock JM, Ducheyne E, et al. Suitability of European climate for the Asian tiger mosquito Aedes albopictus: recent trends and future scenarios. J R Soc Interface. 2012;9:2708-2717.

21. Gjenero-Margan I, Aleraj B, Krajcar D, et al. Autochthonous dengue fever in Croatia, August-September 2010. Euro Surveill. 2011;16(9). pii: 19805 .

\section{Publish your work in this journal}

The International Medical Case Reports Journal is an international, peer-reviewed open-access journal publishing original case reports from all medical specialties. Previously unpublished medical posters are also accepted relating to any area of clinical or preclinical science. Submissions should not normally exceed 2,000 words or
4 published pages including figures, diagrams and references. The manuscript management system is completely online and includes a very quick and fair peer-review system, which is all easy to use. Visit http://www.dovepress.com/testimonials.php to read real quotes from published authors.

Submit your manuscript here: https://www.dovepress.com/international-medical-case-reports-journal-journal 